\title{
An investigation on the strain distribution of resistance welded thermoplastic composite joints
}

\author{
H. Shi ${ }^{*}$, I. Fernandez-Villegas ${ }^{\dagger}$, and H.E.N. Bersee ${ }^{\ddagger}$ \\ Faculty of Aerospace Engineering, Delft University of Technology, \\ Kluyverweg 3, Delft, 2629 HS, the Netherlands
}

\begin{abstract}
In order to better understand the usefulness of single lap shear testing for the characterization of resistance welded thermoplastic composite joints, finite element method (FEM) and digital image correlation measurements (DIC) were combined to investigate the strain distributions of the joints during testing. Glass fibre reinforced Polyphenylene Sulfide (GF/PPS) was resistance welded in aid of a metal mesh. Shear and peel strain distributions were investigated at the joint overlap area. The effect of the resin fillet and metal mesh on the strain distributions and apparent shear strengths was investigated. A comparison between resistance welded and adhesively bonded GF/PPS joints was performed.
\end{abstract}

\section{Introduction}

$\mathrm{O}$ WING to the intrinsic properties of thermoplastic polymers, thermoplastic composites can be joined by melting, autohesion, and consolidation of the matrix material at the joining interface. As an effective thermal joining technique for thermoplastic composites, resistance welding has shown great potential to decrease the manufacturing cost owing to the relatively less manufacturing steps and cheaper tooling, and it has already been used in the production of current commercial aircrafts [1]. Even though resistance welding has attracted quite some attention, better understanding on the welding quality and joint performance is still needed.

Resistance welding of thermoplastic composites has been studied by many authors focusing on the welding process, process modeling, and mechanical performance of the joints. To characterize the mechanical properties of the welded joints, different testing methods like short beam shear test, lap-shear strength test, wedge-insert test, and three-point bending tests have been used [2-4]. Single lap joint (SLJ), usually used for the research of adhesively bonding [5], was mostly adopted for resistance welding of thermoplastic composites due to its simplicity in geometry and convenience for manufacturing. A heating element, usually carbon fibre reinforced thermoplastic prepreg or resin impregnated metal mesh, is used for resistance welded joints, which acts as the weld line. The presence of carbon fibre or metal mesh at the joint interface could influence the material properties of the weld line, and then influence the stress distributions at the joint overlap area. Knowing the stress distributions of the resistance welded SLJ is helpful to better understand the results and relevance of such tests when, for instance, comparing different types of heating elements. However, no research has been published yet on the stress/strain distribution of resistance welded thermoplastic composites.

In this paper, strain distributions of resistance welded thermoplastic composites with metal mesh heating element were investigated numerically and experimentally. A 2D finite element analysis model was developed for the stress/strain analysis. The Digital Image Correlation (DIC) technique was used to measure the strain distributions of the welded joint during the single lap shear tests. Shear and peel strain distributions along the weld line of the resistance welded joint were investigated. The effects of adhesive fillet and metal mesh on the strain distributions and lap shear strengths were studied. A comparison between resistance welded joints and adhesively bonded joints was performed as well.

\footnotetext{
${ }^{*}$ PhD Researcher, AIAA Student Member, Design and Production of Composite Structures, Faculty of Aerospace Engineering, H.Shi@tudelft.nl.

${ }^{\dagger}$ Senior Researcher, Design and Production of Composite Structures, Faculty of Aerospace Engineering.

${ }^{\ddagger}$ Associate Professor, Design and Production of Composite Structures, Faculty of Aerospace Engineering.

1

American Institute of Aeronautics and Astronautics
} 


\section{Experimental}

Cetex ${ }^{\circledR} 8$ harness satin weave glass fibre reinforced PPS (Polyphenylene Sulfide), provided by TenCate, the Netherlands, was used to manufacture the substrates. $8 \mathrm{GF} / \mathrm{PPS}$ semi-preg layered laminates, with a $\left[0^{\circ} / 90^{\circ}\right]_{4 \mathrm{~s}}$ sequence and a size of $580 \mathrm{~mm} \times 580 \mathrm{~mm}$ were consolidated in a hot platen press. The consolidation parameters were: $320^{\circ} \mathrm{C}$ for the processing temperature, $15 \mathrm{~min}$ for the consolidation time, $1.0 \mathrm{MPa}$ for the consolidation pressure, and $15^{\circ} \mathrm{C} / \mathrm{min}$ for the cooling rate. The final thickness of the consolidated laminates was around $2 \mathrm{~mm}$.

Two types of plain woven stainless steel meshes - M24 and M200, provided by Dinxperlo, the Netherlands, were used for resistance welding. M24 mesh has a wire diameter of $0.2 \mathrm{~mm}$ and an opening area of $66 \%$; M200 mesh has a diameter of $0.04 \mathrm{~mm}$ and an opening area of $48 \%$. In order to provide a resin rich area at the weld interface and fill the gaps between the metal wires, one or four layers of PPS resin films with a thickness of $90 \mu \mathrm{m}$ were put between the metal mesh and the substrate for M200 and M24, respectively. To characterize the mechanical properties of the weld line, M24 and M200 were impregnated with one or four layers of PPS film respectively in a hot platen press. The processing pressure was $0.3 \mathrm{MPa}$, temperature $280^{\circ} \mathrm{C}$, and consolidation time 20 seconds.

A custom-built resistance welding setup, as shown in Figure 1, was used in this study. The welded specimen had a substrate length (l_substrate) of $100 \mathrm{~mm}$, joint overlap length (b_overlap) of $12.7 \mathrm{~mm}$, specimen width (b_specimen) of $25.4 \mathrm{~mm}$, and weld line thicknesses (t_weld line) of $0.4 \mathrm{~mm}$ for M24 and $0.08 \mathrm{~mm}$ for M200. All samples were welded with a constant power input of $80 \mathrm{KW} / \mathrm{m}^{2}$ for 60 seconds, and under a welding pressure of 8 bars. GF/PPS tabs with dimensions of $25.4 \mathrm{~mm} \times 25.4 \mathrm{~mm}$ were welded to the substrates with the same type of heating element to keep equal thickness as the joint overlap area, which guarantees the specimen alignment with the loading axis. Resin fillets, made from 3M $9323 \mathrm{~A} / \mathrm{B}$ adhesive, were added to the edges of the overlap for some of the welded samples. The adhesive fillets were cured in an oven of $65^{\circ} \mathrm{C}$ for 2 hours according to the supplier's recommendation. Lap shear tests were performed following the ASTM D1002 standard, except for setting the loading speed as $1 \mathrm{~mm} / \mathrm{min}$ in order to get a good tracking and observation for the DIC camera.

The DIC system, supplied by Limess Messtechnik \& Software GmbH Inc, Germany, was used for measuring the strain distribution of the cross-section of the joint overlap. The experimental setup and specimen dimensions are schematically shown in Figure 2. The surfaces to be tracked were spray-painted to get a fairly uniform random pattern consisting of black speckles on a white background. In this study, the capturing speed of the digital camera was set as 1 frame per second to ensure a robust object tracking. The images were 256 grey levels and had a dimension of $2048 \times 2048$ pixels. Considering the calculation accuracy and computation time, the subset size was selected as 40 pixels and the step size was selected as 9 pixels. The measurement error of the strain field was less than $200 \mu$ strains, which satisfied the requirements of our research.

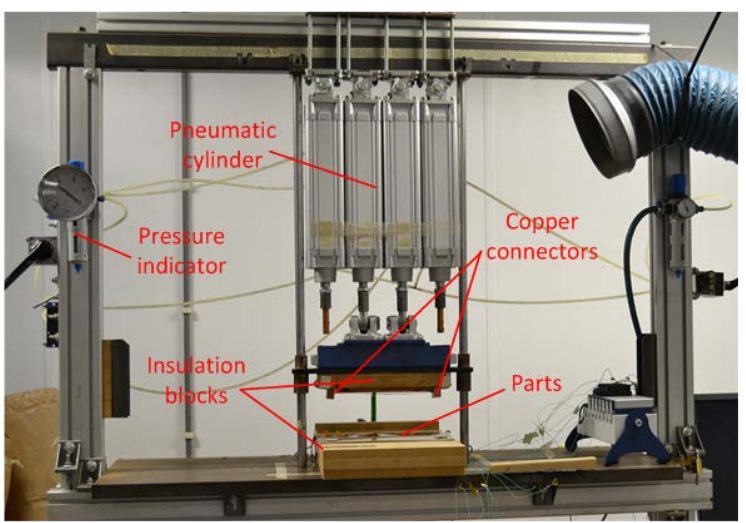

Figure 1. Resistance welding setup

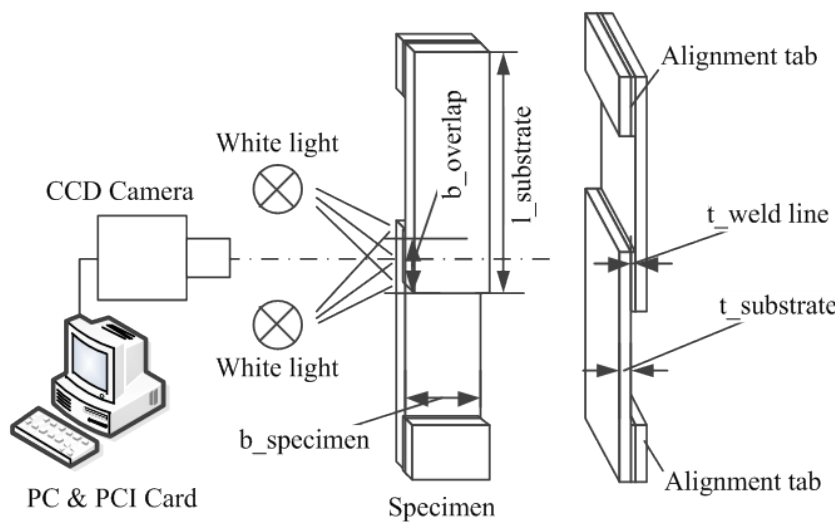

Figure 2. Experimental setup for DIC test

\section{FEM model}

Stress/strain analysis of the resistance welded SLJ was performed by using the finite element method (FEM) software of ABAQUS ${ }^{\circledR}$. A 2D model with the same dimensions of the welded specimen was developed. Linear elastic material properties were used for both the substrates and weld line. In order to simplify the model, the weld line was treated as an isotropic material and the mechanical properties of the PPS impregnated metal meshes were used as the material properties of the weld line. Tensile tests were performed to measure the material properties of the PPS impregnated meshes. Sample dimensions of $100 \mathrm{~mm}$ long, $13 \mathrm{~mm}$ wide, and $0.4 \mathrm{~mm}$ thick were used for the PPS impregnated M24 samples, and 0.08mm thick for the PPS impregnated M200 samples, as shown in Figure 3. In

2

American Institute of Aeronautics and Astronautics 
order to decrease possible damage and stress concentrations on the samples caused by the clamping force during the test, $2 \mathrm{~mm}$ thick and $20 \mathrm{~mm}$ long GF/PPS tabs with a chamfer angle of $30^{\circ}$ were bonded to the ends of the tensile samples using 3M 9323 A/B adhesive. Tensile tests were performed according to ASTM D 3039/D 3039M-08. Young's modulus and Poisson ratio of the weld line were measured by using DIC during the tensile tests, and then the shear modulus was calculated.

The boundary conditions of the lap shear joints were established by defining a hinge for one end of the joint and a roller for the other side, and the loading was defined by an axial force applied at the roller end, as shown in Figure 4 a). A tie constraint was defined for the interfaces between the weld line and the substrate. For the joints having a fillet at the edge, $45^{\circ}$ fillet was modeled at the end of the overlap, as shown in Figure $4 \mathrm{~b}$ ). Interactions between the fillet and the adjacent edges of the joint were defined as tie constraints. 2D planar shell elements were used for the FEM analysis. Structured meshing technique was selected for meshing the substrate and weld line, and free meshing was used for meshing the fillets. Meshes were refined near the overlap area, and further refinement was performed near the edges of the overlap. The mechanical properties of the substrate and weld line are listed in Table 1.

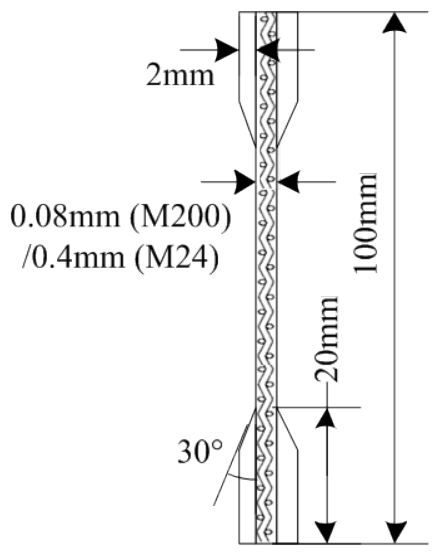

Figure 3. Dimensions of the tensile test sample of PPS impregnated mesh

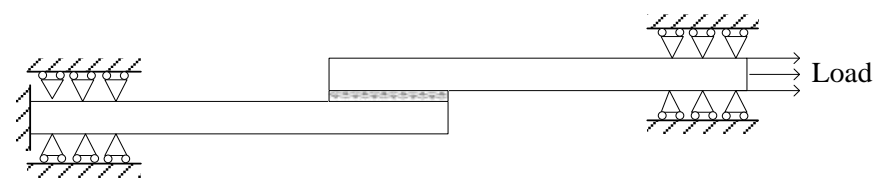

a) Joint without fillet

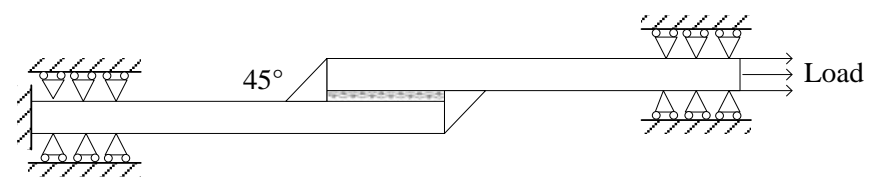

b) Joint with resin fillets

Figure 4. Boundary and load conditions of the resistance welded single lap shear joint in FEM model

Table 1. Material properties used in the FEM model

\begin{tabular}{cccc}
\hline & $\begin{array}{c}\text { Young's modulus (GPa) } \\
\mathrm{E} /\left(\mathrm{E}_{1}, \mathrm{E}_{2}, \mathrm{E}_{3}\right)\end{array}$ & $\begin{array}{c}\text { Poisson's ratio } \\
\mathrm{v} /\left(v_{12}, v_{13}, v_{23}\right)\end{array}$ & $\begin{array}{c}\text { Shear modulus (GPa) } \\
\mathrm{G} /\left(\mathrm{G}_{12}, \mathrm{G}_{13}, \mathrm{G}_{23}\right)\end{array}$ \\
\hline Substrate (GF/PPS) [6] & $22,20,7.22$ & $0.3,0.35,0.3$ & $4.9,2.68,2.68$ \\
Weld line (PPS impregnated M24) & 8.56 & 0.2 & 3.56 \\
Weld line (PPS impregnated M200) & 12.56 & 0.18 & 5.32 \\
Resin (PPS) [6] & 3.8 & 0.36 & 1.4 \\
Fillet (3M 9323) [7] & 2.44 & 0.4 & 0.87 \\
E-glass fibre [8] & 72.4 & 0.2 & 30 \\
\hline
\end{tabular}

\section{Results and discussion}

\section{A. Strain distributions of the resistance welded joints}

Shear is regarded as the primary stress state for the lap shear test, however peel or normal stress could also be responsible for the failure of the joints $[9,10]$, so the peel strain/stress was also investigated in this study. Because strain is the parameter that can be directly measured from the DIC test, the strain distribution was investigated rather than the stress distribution in this study. Figure 5 shows the DIC results of shear and peel strain distributions of the M24 welded GF/PPS joints at a load of 2000N. The level of the shear strain was found higher than the peel strain. As already well known from the studies published on adhesively bonded single lap shear joints [11, 12], shear and peel strain concentrations were also found at the edges of the overlap for the welded joints, which were caused by the unsymmetrical geometry of the single lap shear joint and the differences of material properties between the

\footnotetext{
${ }^{*} \mathrm{E}_{3}, \mathrm{G}_{12}, \mathrm{G}_{13}$ are estimated from the rule of mixtures, $v_{12}, v_{23}$ are given by assumption
} 
substrate and weld line [9]. Because of the strain concentrations there, cracks always initiate from the edges of the overlap area and then grow towards the middle, as can be seen from Figure 6.
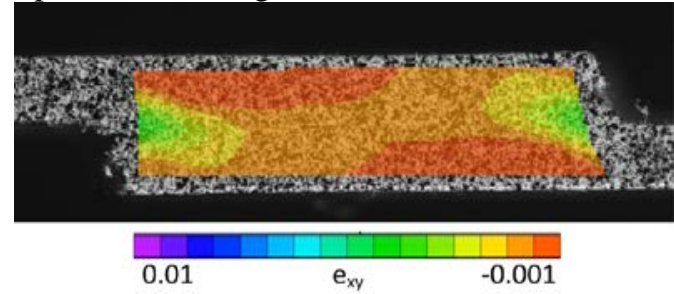

Shear strain distribution (DIC)
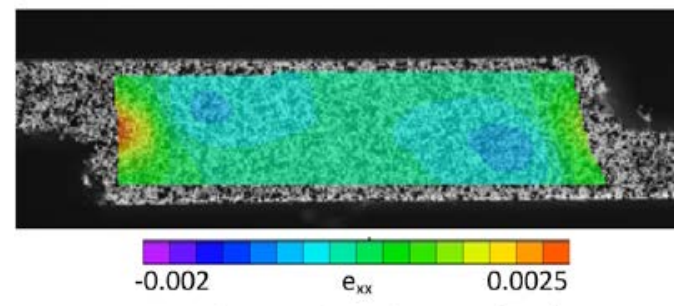

Peel strain distribution (DIC)

Figure 5. DIC results of shear and peel train distributions of M24 welded GF/PPS at a load of $2000 \mathrm{~N}$

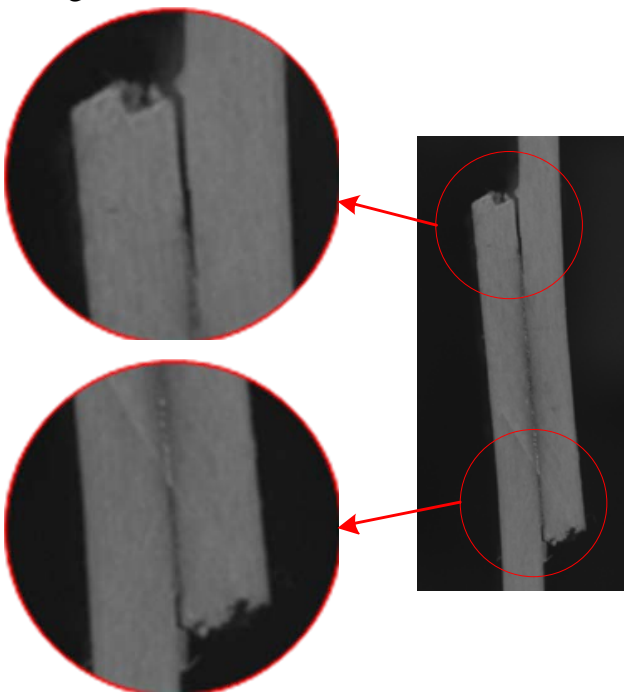

Figure 6. Crack initialization of a resistance welded GF/PPS joint

To simulate the strain distributions for the welded joints, the material properties of the PPS (resin properties) were firstly used for the weld line. As shown in Figure 7, the FEM results showed a much higher shear strain and strain concentrations at the edges of the weld line as compared with the DIC results. As listed in Table 1, the modulus of the PPS impregnated M24 and PPS impregnated M200 were 8.56 GPa and 12.56 GPa respectively, much higher than the modulus of neat PPS (3.8 GPa). Using the equivalent properties for simulation, both shear and peel strain concentrations at the overlap edges were diminished, and a closer agreement was found with the DIC results. Since the mechanical properties of the adhesive could influence the stress distribution of the overlap [13, 14], material property differences between neat PPS and PPS impregnated metal mesh will influence the strain distributions. However, there are still some differences found on the strain distributions between DIC and FEM results, which could be caused by the simplification for the weld line properties and a non-uniform quality of the welds along the weld line.

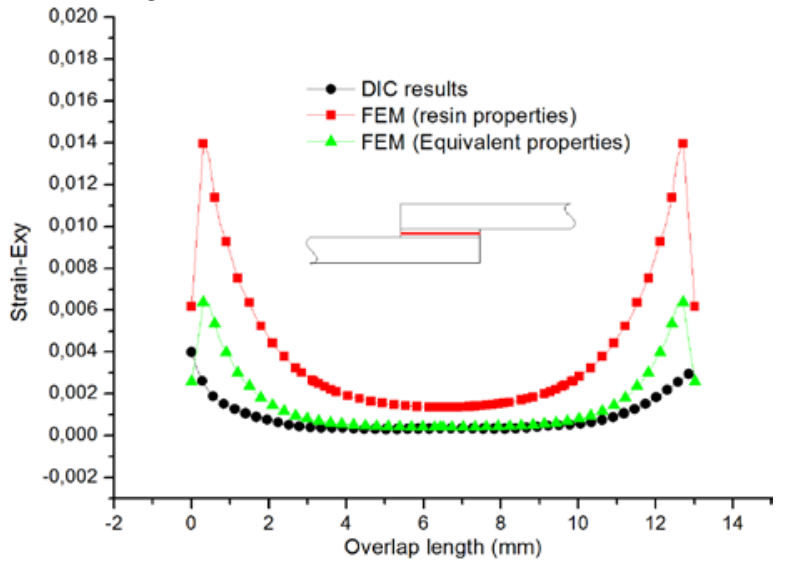

a) Shear strain

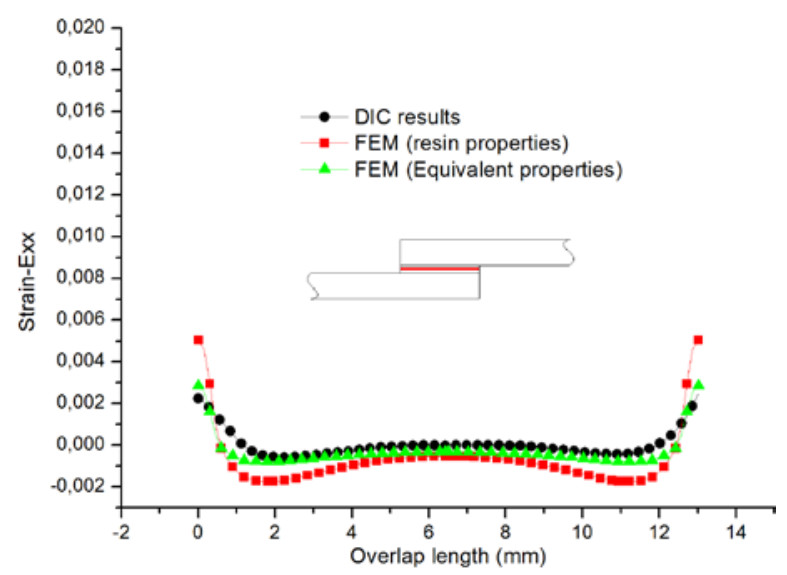

b) Peel strain

Figure 7. Comparison of DIC and FEM results on the shear and peel strain distributions along the middle line of the weld line at a load of $2000 \mathrm{~N}$

\section{B. Effect of resin fillet}

Besides the stress concentrations, poor weld quality at the edges of the overlap also make the edges critical areas for failure. As one of the most important parameters, temperature greatly influences the consolidation quality of the

4

American Institute of Aeronautics and Astronautics 
welds, which is related to the mechanical properties of the welds. During the welding process, the heating element generates heat uniformly at the overlap area. However, different heat transfer conditions existing from the edge to the middle of the joint overlap make the temperature distribution not uniform, being it higher at the middle than at the edges, as shown in Figure 8. Because of the non-uniformity of temperature distribution along the overlap, the consolidation degree at the edges is much lower than at the middle part (see Figure 9), which leads to a relatively lower welding quality at the edges.

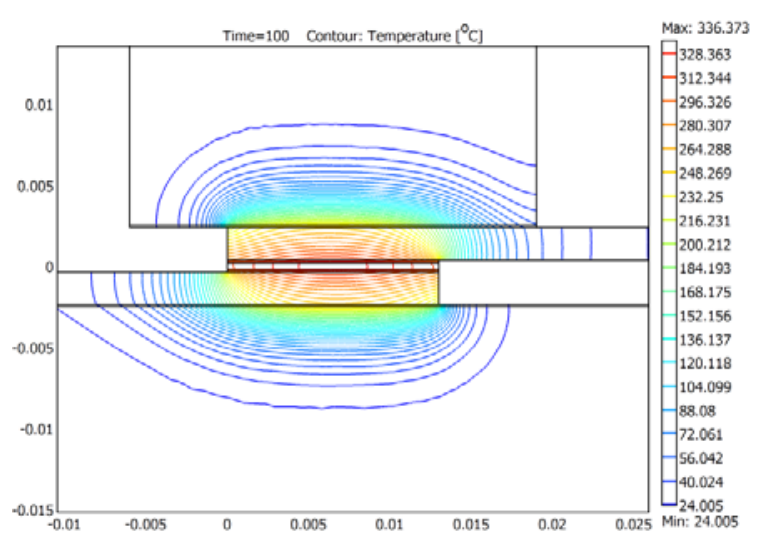

Figure 8. Isothermal lines of the joint during resistance welding that from the welding processing model [15]

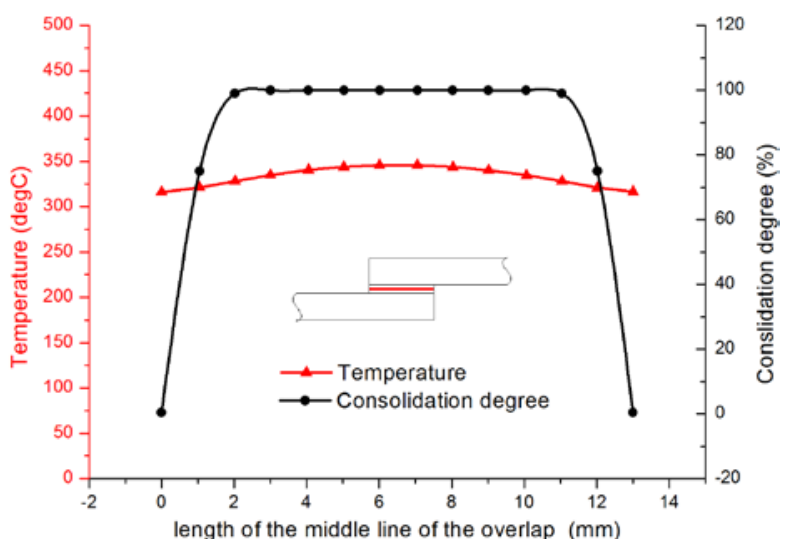

Figure 9. Temperature and consolidation degree distribution along the overlap length predicted from the welding processing model [15]

In order to reduce the stress concentrations at the edges of the overlap, resin fillets were created. Different qualities of substrate edges, and therefore adhesion with the fillet, were obtained by using different cutting methods. A flat edge was obtained if the substrate was cut using a grinding wheel, while a ragged edge was got if the substrate was cut by a shearing cutter. Adhesive fillets were created and bonded to the edges of the joints. DIC results of the strain distributions for joints with and without fillets are shown in Figure 10. The strain distributions of joints with flat edge fillets and ragged edge fillets were similar, while big differences were found between joints with and without fillets. The peel strain concentrations near the edges of the overlap were greatly reduced by the presence of the fillet. Instead of high positive peel strains for the joints without fillet, negative peel strains were found for the joints with fillets. Both the average shear strain level and the shear strain concentrations were reduced for the joints with fillets. FEM results of the strain distribution are shown in Figure 11. Because of the discontinuities of material properties among fillet, weld line, and substrate, jumps of strain distribution curves were found near the fillet areas for the numerical simulation. However, both shear and peel strain concentrations were greatly reduced near the edges of the overlap, which coincides with the results of the DIC measurements.

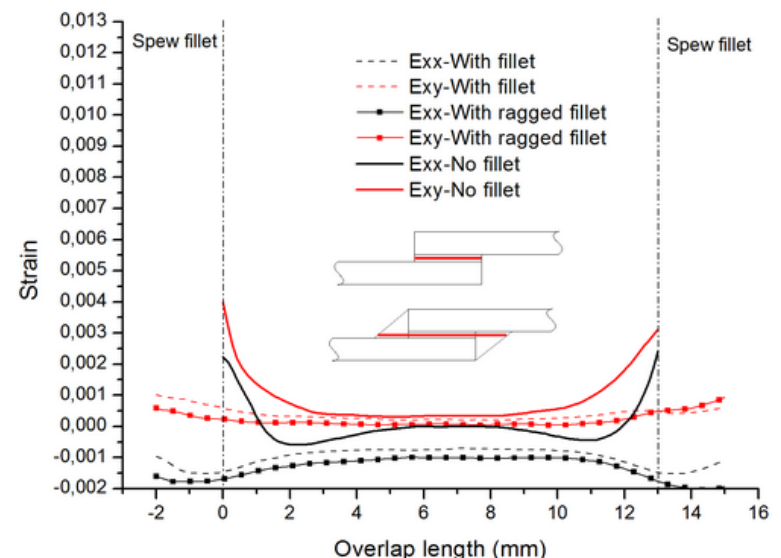

Figure 10. DIC results of the shear and peel strain distributions for joints with and without fillets at a load of $2000 \mathrm{~N}$

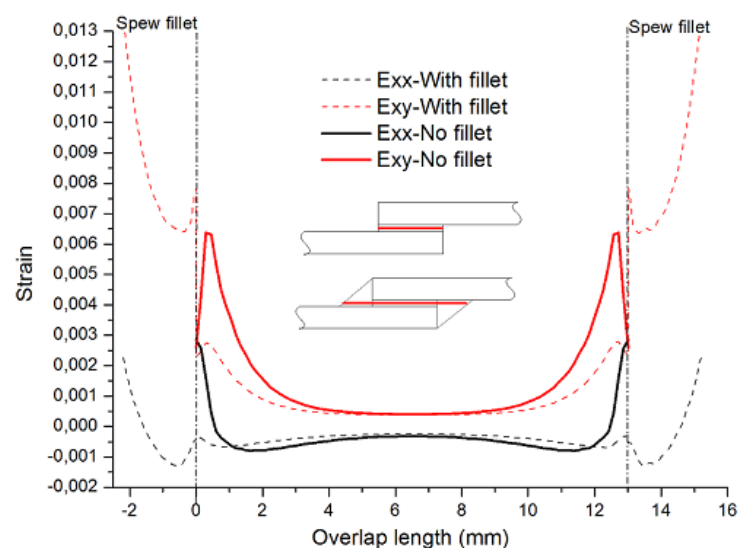

Figure 11. FEM results of the shear and peel strain distributions for joints with and without fillets at a load of $2000 \mathrm{~N}$

As shown in Figure 12, the apparent shear strengths of M24 welded GF/PPS without fillet, with fillets bonded with flat substrate edges, and with fillets bonded with ragged substrate edges were $13.10 \mathrm{MPa}$, 17.87 $\mathrm{MPa}$, and 
24.45 MPa respectively (with coefficients of variation CV of $4.2 \%, 17 \%$, and $11 \%$, respectively). The fillets resulted in a strength increase of $36.45 \%$ for flat-edge substrate samples and $86.6 \%$ for ragged-edge substrate samples, which were much bigger than the typical 12-20\% increase of fillet effect for adhesively bonded composites [16, 17]. Joints having fillets bonded with ragged substrate edges broke at the interface between fillet and substrate, which indicates that the bond quality between the fillet and substrate was poor. While for the joints having fillets bonded with ragged edges, fracture occurred through the fillet, which indicates that the bond quality between fillet and substrate was good. The ragged edge provided a rougher and larger surface to bond with the fillet, which increases the bonding quality. However, relatively big variations were found for the lap shear strengths of the joints with fillets, which could be caused by the geometric shape variations of the fillets owing to the manually manufacturing method and to the random roughness of the ragged edges caused by the cutting process.

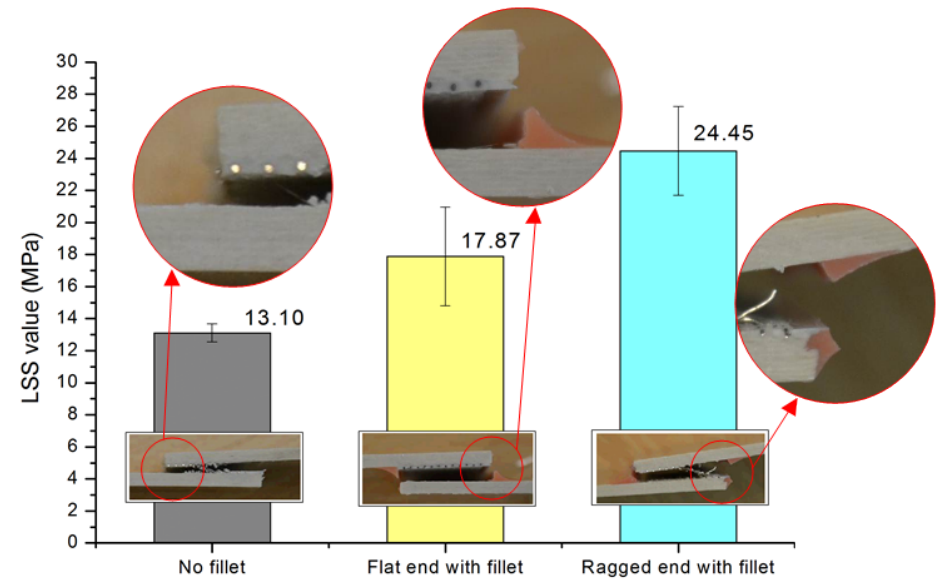

Figure 12. Fillet effects on the lap shear strength of resistance welded GF/PPS with M24

\section{Effect of the heating element}

M24 and M200 metal meshes were used as heating elements for resistance welding of GF/PPS. Figure 13 shows the DIC strain distributions of M24 and M200 welded joints at a tensile load of 2000N. Shear strain was found bigger than the peel strain for both meshes. Lower average shear and peel strains were found for the M200 welded joint than for the M24 joint, which could be caused by the smaller thickness and higher modulus of the M200 weld line. First, the weld line thicknesses of M200 welded joints (about $0.08 \mathrm{~mm}$ ) were smaller than the M24 welded joints (about $0.4 \mathrm{~mm}$ ). As already known for adhesive and fusion bonded joints, that a thinner bond/weld layer could help to increase the lap shear strength [5, 10], which is related to the change of the stress distribution. Secondly, the modulus of PPS impregnated M200 is higher than the PPS impregnated M24, and the differences of the weld line material properties could also influence the stress and strain distributions, which is in accordance with what found in literatures $[13,14]$. A lower shear strain distribution was also found for the M200 welded joint from the FEM results, as shown in Figure 14, which agrees with the DIC results. Different strain concentration levels were found near the edges of the overlap between DIC and FEM results, which could be caused by the singularity problems with the numerical solution. 


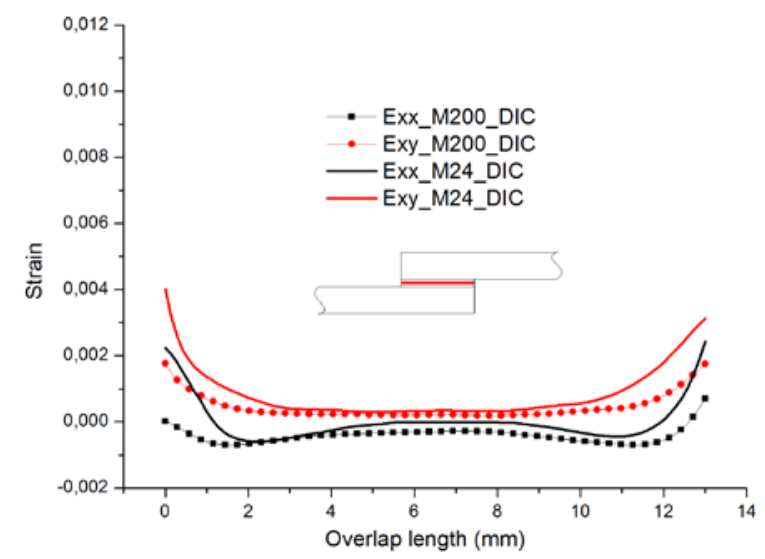

Figure 13. DIC results of shear and peel train distributions along the overlap middle lines of M200 and M24 welded GF/PPS joints

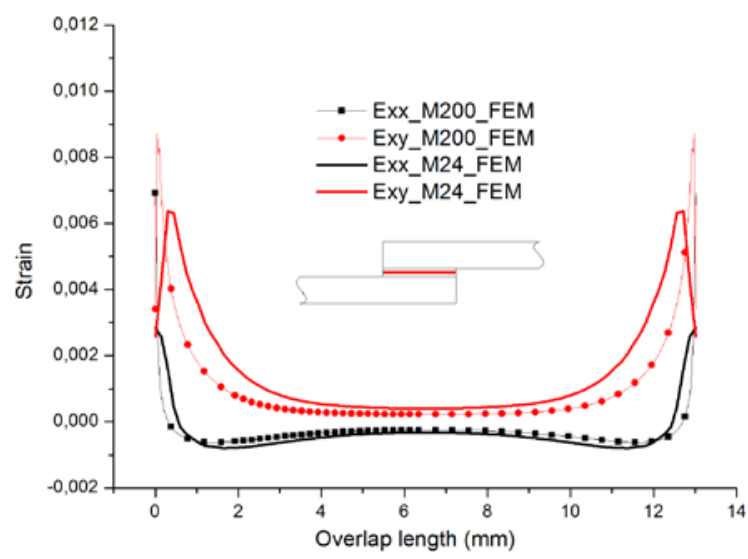

Figure 14. FEM results of shear and peel train distributions along the overlap middle lines of M200 and M24 welded GF/PPS joints

As shown in Figure 15, the apparent shear strengths for the M24 and M200 welded joints were 13.10MPa (with a CV of $4.2 \%$ ) and $15.49 \mathrm{MPa}$ (with a CV of 2.3\%). An increase of $18 \%$ was obtained for joints welded using the M200 mesh, which could be caused by the difference of the strain/stresses owing to the different weld line thickness and stiffness. In addition, different wire diameters and opening areas of these two metal meshes provide different areas of mesh in contact with the resin, which could influence the qualities of mechanical interlocking. Since the mechanical interlocking between metal wires and polymer has been found more important than the interfacial bonding for the resistance welded joints [3], a better mechanical interlocking quality is beneficial for improving the welding quality. As shown in Figure 16, there are more areas of cohesive failure and more wires torn from the resin for M24 welded sample than M200 welded sample, which indicates different mechanical interlocking qualities between M24 and M200 welded samples.

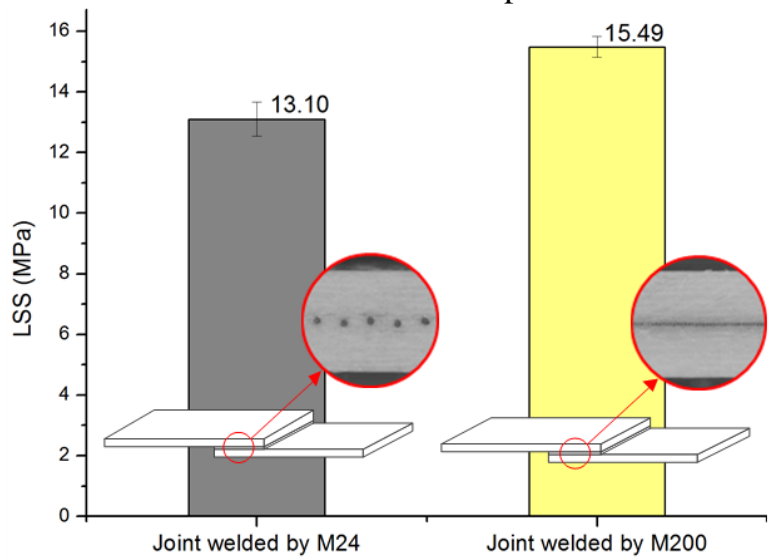

Figure 15. Lap shear strengths of M24 and M200 welded GF/PPS joints

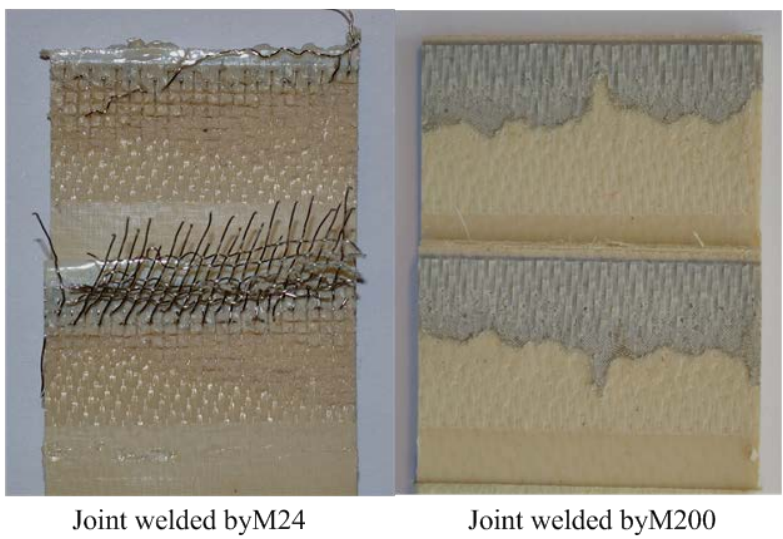

Figure 16. Fracture surfaces of joints welded by M24 and M200

\section{Comparison with adhesively bonded joints}

To characterize the differences of strain distributions between welded and adhesively bonded thermoplastic composites, 3M 9323 adhesive bonded GF/PPS joints were also investigated. In order to get a good adhesion between substrates and bond line, the surfaces of substrate were sanded, cleaned, and plasma treated prior to the bonding process. The bond line thickness was kept to $0.3 \mathrm{~mm}$. The DIC results of the shear and peel strain distributions of welded and bonded joint are shown in Figure 17, obvious differences of peel strain distributions were found near the edges of the overlap. The big peel strain concentration in the welded joints could be caused by the poor weld quality there. A notorious spew fillet resulting from the adhesive bonding process (see Figure 17) could greatly influence the strain distribution of the bonded joints. As shown in Figure 18, the average lap shear strengths of the bonded joints and M24 welded joints were 7.93 MPa (with a CV of 17\%) and 13.10MPa (with a CV of $4.2 \%$ ). Welded joints performed better than the bonded ones. Typical fracture surfaces of these two types of joints 
are shown in Figure 18. Interfacial failures were found in the bonded joints, indicating a poor adhesion at the interface owing to the high chemical resistance of PPS. A combination of interlaminar and cohesive failures was found for the welded joints, which indicates good joining between the impregnated heating element and the substrates.

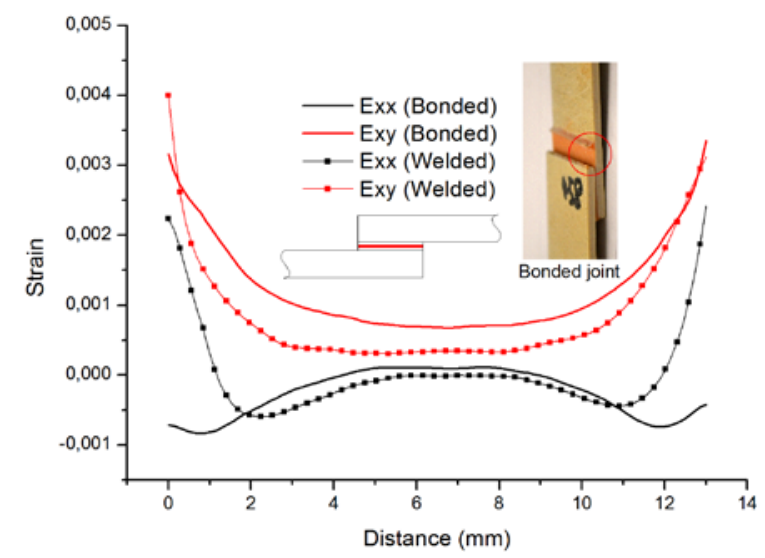

Figure 17. DIC results of strain distributions of welded and bonded GF/PPS joints

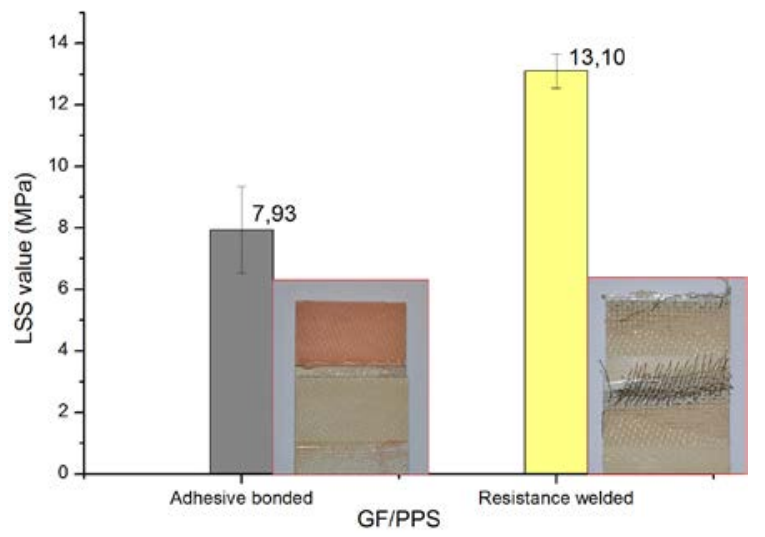

Figure 18. Lap shear strengths and fracture surfaces of welded and bonded GF/PPS joints

\section{Conclusion}

Resistance welded GF/PPS single lap joints were studied. The effects of different metal mesh heating elements and resin fillets on the strain distributions at the joints were investigated using DIC and FEM methods. Strain distributions of resistance welded joints and adhesively bonded joints were compared as well. The following main conclusions can be drawn from the results of this study:

1. The edges of the resistance welded joints are the weakest areas due to the load eccentricity and the heat transfer related issues during the welding process. The use of fillets greatly reduces the strain concentrations at the overlap edge, which results in a lap shear strength increase of $86.6 \%$, which is a much more remarkable effect than what usually observed on bonded joints.

2. M200 welds show lower strain concentrations near the edges of the overlap and result in higher lap shear strength than M24 welds, which is believed to be a combination of lower stress concentrations and perhaps a better interlocking of the polymer and the mesh.

3. The adhesive bonded joints show a more favorable strain distribution (much less peel strain concentration) but lower lap shear strength than the welded joints, which is due to the chemical inertness of PPS.

4. It is difficult to fully characterize the resistance weld quality only from single lap shear testing because both the stress distribution and lap shear strength are influenced by the imperfections of the resistance welding process (bad quality welds at the edges that aggravate the stress concentration issue) and the type of the heating element (differences in weld thickness and mechanical interlocking quality).

\section{Acknowledgments}

This work formed a part of TAPAS project sponsored by Airbus and Dutch aerospace partners. The authors would like to thank Ten Cate Advanced Composites and Wire Weaving Co. Ltd, Dinxperlo in the Netherlands, for providing their materials.

\section{References}

${ }^{1}$ Offringa, A., "Thermoplastics in Aerospace, New Products Through Innovative Technology," SAMPE Journal, Vol. 41, No. 7, pp. 19-27, 2005

${ }^{2}$ Stavrov, D., and Bersee, H. E. N., "Resistance welding of thermoplastic composites-an overview," Composites Part A: Applied Science and Manufacturing, Vol. 36, No. 1, pp. 39-54, 2005

${ }^{3}$ Dubé, M., Hubert, P., Yousefpour, A., and Denault, J., "Resistance welding of thermoplastic composites skin/stringer joints," Composites Part A: Applied Science and Manufacturing, Vol. 38, No. 12, pp. 2541-2552, 2007

${ }^{4}$ Dubé, M., Hubert, P., Gallet, J. N. A. H., Stavrov, D., Bersee, H. E. N., and Yousefpour, A., "Fatigue performance characterisation of resistance-welded thermoplastic composites," Composites Science and Technology, Vol. 68, No. 7, pp. 17591765, 2008 
${ }^{5}$ da Silva, L. F. M., Carbas, R. J. C., Critchlow, G. W., Figueiredo, M. A. V., and Brown, K., "Effect of material, geometry, surface treatment and environment on the shear strength of single lap joints," International Journal of Adhesion and Adhesives, Vol. 29, No. 6, pp. 621-632, 2009

${ }^{6}$ http://www.tencate.com, "CETEX® PEI Technical Data." 2009

${ }^{7}$ Lees, D. E., and Hutchinson, A. R., "Mechanical characteristics of some cold-cured structural adhesives," International Journal of Adhesion and Adhesives, Vol. 12, No. 3, pp. 197-205, 1992

${ }^{8}$ http://www.matweb.com/search/DataSheet, "E-Glass Fiber, Generic." 2012

${ }^{9} \mathrm{He}, \mathrm{X}$., "A review of finite element analysis of adhesively bonded joints," International Journal of Adhesion and Adhesives, Vol. 31, No. 4, pp. 248-264, 2011

${ }^{10}$ Smiley, A. J., Chao, M., and Gillespie Jr, J. W., "Influence and control of bondline thickness in fusion bonded joints of thermoplastic composites," Composites Manufacturing, Vol. 2, No. 3, pp. 223-232, 1991

${ }^{11}$ Goland, M., and Reissner, E., "The Stresses in Cemented Joints," ASME, Journal of Applied Mechanics, Vol.11, pp. A17A27, 1944

${ }^{12}$ Volkersen, O., "Die Nietkraftverleitung in zugbeanspruchten Nietverbindungen mit konstanten Laschenquerschnitten," Luftfahrtforschung, 15, pp. 41-47, 1938

${ }^{13}$ Min, Y., Jialing, Y., Xiaoling, Z., Dingfeng, Z., Jianli, L., and Jingrong, H., "The Numerical Analysis on the Weld-Bonded Joints with Bi-adhesive," Second International Conference on Computer Modeling and Simulation, pp. 25-28, 2010

${ }^{14}$ Tsai, M. Y., and Morton, J., "An investigation into the stresses in double-lap adhesive joints with laminated composite adherends," International Journal of Solids and Structures, Vol. 47, No. 24, pp. 3317-3325, 2010

${ }^{15}$ Shi, H., F.Villegas, I., and Bersee, H. E. N., "Modelling of Heat Transfer and Consolidation for Thermoplastic Composites Resistance Welding," 18th International Conference on Composites Materials, Jeju, South Korea, 2011

${ }^{16}$ Kim, K.-S., Yoo, J.-S., Yi, Y.-M., and Kim, C.-G., "Failure mode and strength of uni-directional composite single lap bonded joints with different bonding methods," Composite Structures, Vol. 72, No. 4, pp. 477-485, 2006

${ }^{17}$ Yang, Y. H., Wu, L. Z., Guo, Y., and Zhou, Z. G., "Effect of Spew Fillets on Strength of Single-Lap Adhesive Composites Joints," Advanced Materials Research 239-242, pp. 810-814, 2011 